\title{
The Role Dilemma and Solution Strategy of Female Leadership Development in Colleges and Universities from the Perspective of Gender Mainstreaming
}

\author{
Ziqiong Huang \\ School of Public Management, Jinan University, Guangzhou, China \\ Email: jnuziqiong@163.com
}

How to cite this paper: Huang, Z. Q (2020). The Role Dilemma and Solution Strategy of Female Leadership Development in Colleges and Universities from the Perspective of Gender Mainstreaming. Open Journal of Social Sciences, 8, 109-118. https://doi.org/10.4236/jss.2020.82010

Received: January 15, 2020

Accepted: February 21, 2020

Published: February 24, 2020

Copyright $\odot 2020$ by author(s) and Scientific Research Publishing Inc. This work is licensed under the Creative Commons Attribution International License (CC BY 4.0).

http://creativecommons.org/licenses/by/4.0/

\section{(c) (i) Open Access}

\begin{abstract}
In order to break the conflict between family and work, lack of work self-efficacy, and even fall into the dilemma of job burnout, this paper, from the perspective of gender mainstreaming, deeply analyzes the reasons why the development of female leaders in colleges and universities falls into the dilemma. The development of female leaders in colleges and universities lacks the support of social culture, and there are institutional obstacles such as the imperfection of organizational assessment mechanism. Therefore, this study proposes a more structured and systematic development strategy. On the one hand, the organization should actively promote the establishment of female leadership assessment and evaluation management mechanism embedded in the social gender mainstreaming, and accelerate the socialization process of housework. On the other hand, it is necessary to strengthen the cognition of female leaders in colleges and universities so as to obtain good to great leadership, in a number of measures to promote the role change of female leaders in colleges and universities, highlight the role in social development, truly release the "gender dividend" in colleges and universities.
\end{abstract}

\section{Keywords}

Female Leaders in Colleges and Universities, Role Dilemma, Crack Strategy, Gender Mainstreaming

\section{Question}

The report of the $19^{\text {th }}$ National Congress of the Communist Party of China focuses on the needs of the people, emphasizes once again the cultivation and im- 
plementation of the socialist core values, and clearly puts forward "adhere to the basic national policy of gender equality, protect the legitimate rights and interests of women and children, and actively promote the process of gender mainstreaming". In the new era, the development of "new women" indicates that gender difference is no longer the only standard of social division of labor. The new social pattern has a profound impact on all kinds of social groups. Whether it is government or enterprise departments, the heterogeneity and change of the leadership team have long been indispensable. The women's leadership team with strength and softness gradually occupies an important position, especially in the fields of education, health and employment. As an important education base to carry out the basic national policy of equality between men and women and cultivate socialist core values, colleges and universities have gradually highlighted the significance of equal rights.

According to the 2017 China Education Statistics Yearbook, among the 2.448 million faculty and workers, there were 163,000 women. The composition of full-time female teachers, administrative staff, teaching auxiliary staff and working staff were $33.4 \%, 6.8 \%, 5.2 \%$ and $1.8 \%$ respectively in 2016 . The number of female leaders above the middle-level management is increasing. But behind the visible organizational structure, gender mainstreaming puts forward new challenges to the internal operation of informal organizations, and also puts forward new requirements for the role of female leaders in the organization and the ability structure they should have. The career development in colleges and universities has higher specialization. Even if women go to the management level, there are different degrees of differences with men in post, title, scientific research, teaching, family, psychology and other levels. There are more excellent women, but the bottle mouth that makes them excellent seems to be shrinking.

Therefore, from the perspective of gender mainstreaming, this paper takes the female leaders in colleges and universities as an example to see the barriers of their progress in the "organization society family personal development" level, in order to effectively solve the role dilemma in the face of various institutional and non institutional obstacles, improve their ability of balance and coordination, and form a joint force of organizational gender.

\section{Gender Analysis of Female Leaders in Colleges and Universities}

In the meditation on management, Henry Mintzberg put forward that "organizations need cultivation, care and care, and constant and stable care. Love is a more feminine way of management, and women have more advantages.".In terms of anatomy, physiological sex is determined by biological genetic factors and does not have social differences. However, under the specific cultural background, both sexes will show their personality characteristics and behavior patterns that are consistent with the social expectations and requirements for their physiological identity, which is called gender. With the Beijing Declaration and 
platform for action of the fourth women's Congress of the Federation in 1995, gender awareness was mainstreamed into decision-making. Gender equality in a wide range of areas under gender mainstreaming has attracted attention. With the release of the bonus of women's higher education, the growth and career development of women's leadership has attracted a high turning point. Therefore, We should advocate replacing physical gender with social gender or social role, promote gender equality in opportunities, rights and obligations, resource treatment and evaluation, and achieve substantive equality and equity between men and women (Daly \& M, 2005).

As an academic holy land, the professional development of colleges and universities needs a stronger foundation of professional and academic ability. University leaders need not only profound professional knowledge background, excellent administrative professional ability, but also comprehensive tension. Compared with men's steady and strong courage, women's leaders are more good at democratic decision-making through delicate cooperation and communication, which is convenient for win-win cooperation within the organization. But the development of gender mainstreaming (Grosser \& Moon, 2005), not only simply from the number or proportion of women participating in leadership and decision-making, but also from whether the women participating in leadership or decision-making represent the interests of women groups and speak for women's equality. Promote the development of internal and social policies towards gender equity, create favorable and mutually beneficial conditions, so as to let more excellent women participate in university leaders and decision-making.

As a high intellectual group with leadership ability, female leaders in Colleges and universities have less time and opportunities to continue their research in academic achievements and academic achievements after taking relevant leadership positions. They are in the roles of "female leader", "female teacher" or "female researcher", as well as family roles such as "mother", "wife" or "daughter", and even all kinds of social part-time workers (Crystal et al., 2010). They need to deal with the balance of "society family work personal development" at the same time. As a result, female leaders in Colleges and universities are faced with the dilemma of multiple role conflicts, resulting in fuzzy roles and career development bottlenecks.

\section{The Reasons Why the Development of Female Leaders in Colleges and Universities Is in Trouble}

From physical gender to social gender, to achieve gender equality and justice, we need to recognize the dual characteristics of female leaders who play multiple roles. Women's development is not only based on the number of women in management, but also the most important thing is to achieve qualitative equality, namely gender mainstreaming (Alice, 2003). Female leaders in Colleges and universities should not only carry out teaching and scientific research, but also manage, organize and coordinate their families, Due to the limitation of time and 
energy, conflicts and ambiguities between different roles often arise. The root of this problem should not only be attributed to the ability of female leaders in Colleges and universities, but also be affected by the social support environment, imperfect assessment mechanism and the conflict between "family and work" which is contrary to the equal employment of women. The interest demands and development needs of female leaders in Colleges and universities are in trouble, which leads to negative emotions such as job burnout and low sense of self-efficacy.

\subsection{Lack of Social Support System Hinders the Improvement of Management Ability of Female Leaders in Colleges and Universities}

The social support system, especially the cultural tightness in the social and cultural environment, affects the improvement of women's leadership and management level. With the social transformation and cultural change, the inherent male centered power relationship is constantly changing, and women's voice in the field of equal employment and career development is gradually strengthened. New social ideas have been breaking through the shackles of traditional women's roles, and women's development has gained more opportunities and rights. However, it has not established a loose cultural support matching with women's equal employment (Hoyt \& Simon, 2011). At the same time, the society advocates women's equal employment, but it has established a strict culture that requires them to keep both career and family, with family as the main business and auxiliary business. Under this kind of double standard, female leaders are often in a dilemma because they can't take care of each other completely.

Strict culture is constrained by rigid social norms and codes of conduct. Social and cultural tolerance is low. Women are unilaterally required to achieve equal employment development and achieve specific requirements and goals. It is easy to ignore the rationality and efficiency of policies and social support. To some extent, it precipitates into a deep inferiority complex of women. They have developed the psychology of being content with the status quo, which conflicts with the spirit of being independent, daring to innovate and pioneering required by the leading role. Especially for female leaders in Colleges and universities, they are more likely to be given the image of "her" era model, female spokesperson, perfect winner and so on, but they do not give the support to cultivate and strengthen self competitiveness. The freedom of university does not mean the autonomy of leaders' development. The sharing and compensation mechanism of women's childbearing and labor protection costs has not been perfected. The conflict between jobs and working abilities and time directly affects the competitiveness and promotion space of university women leaders.

\subsection{The Imperfection of Organizational Assessment Mechanism Causes Female Leaders in Colleges and Universities to Face Academic Glass Ceiling}

It is a typical situation of role conflict that female leaders in Colleges and univer- 
sities take on various social roles. Because of the particularity of professional quality and age level, when the role cannot be coordinated, it is inevitable to experience the trouble of role conflict.

As a gathering place for academic professionals, academic achievement is an important standard for the development of individual academic status and academic discourse power. The breadth and depth of academic knowledge not only requires the independence and freedom of academic innovation, but also requires higher personal time and energy investment. In fact, most of the work functions of female leaders in Colleges and universities are mostly defined as interpersonal or information roles, which are subordinate and facing development obstacles.

At the same time, in the performance evaluation system of teacher training, assessment, post title, etc., gender is not considered as one of the standards for the improvement of the corresponding policy rules and evaluation system, nor the impact and difference of gender differences on the development of male and female teachers and leaders in the actual situation. Therefore, this seemingly unified and fair policy and evaluation system is essentially lack of gender mainstreaming awareness, and the impact of women's physiological and psychological characteristics and social division of labor on their own career development. With academic achievements as the main standard, female leaders in Colleges and universities are more likely to face the role conflicts caused by academic research, family division of labor and leadership work. Compared with men, female leaders are less involved in informal network communication, and information acquisition and support mainly come from work and life affairs (Prudence, 2009). It is common to see unfair evaluation of leadership ability and work efficiency. Female leaders in Colleges and universities have less free time, less opportunities to participate in academic exchanges and further studies, and their own academic research has been negatively affected. Their academic achievements are at the existing level, which makes them prone to fall into the awkward situation of being engaged in both academic career and lack of innovation. As a result, their "upward mobility" in academic career is blocked and their academic development is blocked Land.

\subsection{Family and Marriage Pressures Strengthen Negative Emotions and Behaviors of Female Leaders in Colleges and Universities}

Although women have made some achievements in all walks of life, more women are full of the voice of "work stability, family first". It seems to be a priority for women to balance their inner conflicts by neglecting work and family, obeying the three self roles of "daughter, wife and mother" and the traditional social role of "husband and son". However, for a married female university leader who has been a mother, many tasks will inevitably occupy too much family role space, unable to bear the responsibilities of a wife and mother, which makes the female leaders tired of coping and energy. At the same time, when the social 
status and professional prestige of a wife in a family are significantly better than that of her husband, female leaders are more likely to feel the pressure from the other half's psychological imbalance and external comments. In the past, the housework mainly undertaken by women had to be further shared by their husbands. If the communication between the two sides was not smooth, it would easily lead to conflicts.

The disharmony between marriage and family, high workload and huge social competitive pressure leads to negative emotions such as job burnout, physical fatigue and so on. Under the influence of family affairs, women leaders in Colleges and universities tend to fall into the dilemma of job burnout, which makes it difficult to solve all kinds of contradictions encountered in the process of work, to deal with themselves, to accumulate for a long time and even to become serious social psychological problems.

\subsection{Fuzzy Role Cognition Weakens Self-Efficacy of Female Leaders in Colleges and Universities}

Because some university female leaders can't adapt to the change of multiple roles quickly when they are promoted and competent, so as to achieve professional maturity and professional growth. As a result, they are still struggling to move forward even though they show a strong and independent style. Each role is seizing the limited time resources, which leads to the fuzzy role of individual in self cognition, and it is difficult to change smoothly when entering different roles. This kind of vague role makes female leaders in Colleges and universities at a loss. It not only affects the management work and family harmony, damages the image of oneself, and is not conducive to improving self leadership.

At the same time, compared with men, female university leaders are used to doing things step by step, and lack of understanding and attention to strategic issues and major decisions of organizational development It's easy to have attachment psychology and be willing to play a supporting role in the work, so the idealism is more intense. This kind of incompetence causes pressure on the work of female leaders. Therefore, in the face of the pressure and troubles in the real management work and life, they often feel lost and confused, and their sense of self-efficacy is reduced, which is not conducive to their own career development.

\section{Solving Strategies: The Way to Solve the Development Dilemma of Female Leaders in Colleges and Universities}

When the number of female leaders increases to a certain number, the market economic benefits of their leadership process will be significantly improved, resulting in "gender dividend". This economic force highlights the social function of women's development and promotes the further development of gender mainstreaming. As a catalyst to achieve gender equality and social equity, gender mainstreaming has changed the traditional way of measuring by quantity, focused on women's development influence and equity in policy design and implementation, and rebuilt the social system and norms of gender development 
through structured and systematic analysis. For female leaders in Colleges and universities, work and family belong to two different social systems, but they all belong to their own development needs. Conflicts among different roles often lead to the development dilemma of female leaders in Colleges and universities (Book, 2001). It is urgent to embed the concept of gender mainstreaming, optimize the assessment mechanism of talent management in Colleges and universities, coordinate the conflict between family and work plan, improve their leadership, rebuild and enhance their own right of discourse for development.

\subsection{Establishing the Management Mechanism of Female Leadership Assessment and Evaluation Embedded in Gender Mainstreaming in Colleges and Universities}

Female leaders in Colleges and universities are highly specialized knowledge groups. Academic nature is its essential attribute. Therefore, we should have a correct understanding of the value of the development and utilization of human resources to ensure that both sexes in Colleges and universities enjoy equal development rights. It is necessary to establish and improve a structured and systematic assessment and evaluation mechanism with gender mainstreaming as the main line, and promote government departments, colleges and universities, social organizations, families and media to form a joint force to jointly supervise, so as to improve the selection and promotion mechanism of female leaders in Colleges and universities.

As a new process of integrating the concept of gender equality with policy-making, gender mainstreaming fully considers the differences of experience, thinking mode, responsibilities and rights, opportunities and concepts between the two sexes. We should get rid of the way of emphasizing equal treatment only based on individual standards, preferential treatment and special provisions, and start from the overall interests of the group. We should use the fair strategy to optimize the organization's gender structure and internal personnel training strategy. At present, from the perspective of the overall development of the leadership, the lack of gender awareness often results in the policy "equality and injustice", which will inevitably lead to the obvious short board effect of women in the organizational development, and the gender advantage is difficult to play, or even the gap is widened.

First of all, it is necessary to enhance the gender awareness of policy design subjects. Gender equality in policy is not only highlighted by the word "women". Looking back at the relatively disadvantaged women, the majority of university leaders are male groups, which are inevitably affected by their own patriarchal culture in the formulation of policies and regulations, ignoring the needs of female leaders (Offermann, 1986). Therefore, it is necessary to improve the proportion of female leaders in decision-making and the intervention guarantee mechanism, so as to avoid gender blind spots and design defects in policy-making, and improve their discourse power in the evaluation and promotion mechanism. Secondly, the decision-making concept of equal treatment trans- 
formed into equal influence will further optimize the personal ability training mechanism of female leaders in Colleges and universities. Improve the planning consciousness of female leaders in Colleges and universities for their academic, management and family work, develop their potential from the organization and personal development, and make work plans to ensure the stability and long-term work.

Provide more opportunities for communication and leadership training, provide pre job training opportunities, and shorten the initial period of maladjustment for female leaders in Colleges and universities. Finally, we should pay attention to the training of female leaders at the grassroots level and the development of human capital, establish personal training files, and form a talent pool and think tank for female leaders in Colleges and universities. We should establish a gender evaluation mechanism based on gender mainstreaming, ensure fair competition between female leaders and men in the selection process through policies, and improve the independence and freedom of development of female leaders in Colleges and universities.

\subsection{Accelerate the Socialization of Housework and Promote the Role Change of Female Leaders in Colleges and Universities}

According to Engels, "the first prerequisite for women's liberation is that all women return to the public service", rather than being tied to private labor without economic reward. At present, housework still takes up a lot of time and energy of women in the family. From the perspective of individual women, housework is undoubtedly an important obstacle to women's development. It has a profound impact on women's coordination of roles and tasks in family, society and organization. The primary task of female leaders in Colleges and universities is to realize the smooth transformation of their roles, reduce the time and energy of housework, and realize the socialization of housework. At the same time, we should use all kinds of home appliance functions to reduce the time consumed in housework. Therefore, it can be better put into the work of scientific research and university organization and management. It is an important measure for female leaders in Colleges and universities to alleviate the family work role conflict, and to enhance the internal motivation of the sense of work value and achievement.

By means of paid means, the contents of housework are simplified and transferred out. Updating the intelligent and electronic way of housework is more in line with the dynamic development mode of modern family life. At the same time, the government should improve the infrastructure, community public service capacity, promote the care and Trusteeship of the elderly and children in the community, so as to reduce the burden and worries of women and family care. The socialization of housework is not only the individual liberation of female leaders in Colleges and universities, but also promotes the development of the whole society. Gender mainstreaming can not only rely on the change of in- 
dividuals within the family, but also need the macro promotion of social structure and the establishment of social support network system.

\subsection{Strengthen the Cognition of Female Leaders in Colleges and Universities, and Shape the Leadership from Good to Great}

The development of female leaders in Colleges and universities not only depends on the optimization of external policy environment, but also on the reconstruction of self social cognition and role cognition. We must master the way of coordination and balance between career development and family relations. Women's leadership is a kind of flexible management mode formed by women's decision-making process, management mode, communication and coordination in the leadership role, including the ability to resolve conflicts in a balanced way, selective decision-making method, and communication mode.

After a precise judgment of the actual work and a clear understanding of the multiple roles of self, we should gradually improve the coordination of the role transformation between teachers and administrators, judge the development trend of things quickly and give the decision-making power of specific measures, balance the role transformation between career and family affairs, academic and administrative affairs, personal growth and organizational development. As a leader, we should improve the ability to influence the LED, such as the attraction of formal or informal relationships between teachers and students, colleagues, enterprises, government agencies and other social institutions, as well as the flexibility of democratic management and good communication. Only in specific affairs to explore learning, and constantly improve working skills and leadership art. Eliminate external doubts about their leadership ability through real work achievements. Good at communication in the workplace, win trust and help from superiors, colleagues and subordinates, and be good at expressing in the family, improve family feelings and get more understanding and support. Only by resolving the conflicts, can we really improve the advantages of female leadership development and realize the self-worth from good to great.

\section{Conclusion}

According to this study, based on the perspective of gender mainstreaming, on the one hand, in the era of knowledge economy, as the main force to promote women's progress and female intellectuals' representatives, the rigid and flexible characteristics of female leaders in colleges and universities make their roles in social development increasingly prominent, and become the main force to promote women's progress and female intellectuals' representatives. Female leaders in colleges and universities play an important role as administrators and leaders in the education industry. On the other hand, women leaders in colleges and universities are multi-functional, lack of social and cultural support, incomplete organizational assessment mechanism and other institutional barriers, which of- 
ten lead to difficulties in coordinating the time and energy conflicts between family and work, reduce their sense of self-efficacy, and even fall into the plight of job burnout. Their development still faces many barriers. Therefore, we should gradually improve the relevant assessment and evaluation management mechanism of female leaders in colleges and universities, and speed up the socialization process of housework. At the same time of changing roles, female leaders in colleges and universities should actively cultivate their own "soft" management ability, actively enhance their willingness to lead, give positive psychological hints to themselves, adjust their mentality, deal with the contradictions and conflicts brought by multiple roles with a peaceful heart, and improve their own situation from inside to outside. When dealing with the conflict between family role and work role, female leaders in colleges and universities should be satisfied rather than perfect. Only by giving up can we gain, distinguishing priorities and taking all factors into consideration, can female leaders in colleges and universities truly realize the adaptability of their own abilities and leadership roles.

\section{Conflicts of Interest}

The author declares no conflicts of interest regarding the publication of this paper.

\section{References}

Alice, H. E. (2003). The Rise of Female Leaders. Zeitschrift Fur Sozialpsychologie, 34, 123-132. https://doi.org/10.1024//0044-3514.34.3.123

Book, E. W. (2001). Why the Best Man for the Job Is a Woman: The Unique Female Qualities of Leadership. Bottom Line, 14, 120. https://doi.org/10.1108/bl.2001.17014dae.001

Crystal, L. H., Stefanie, K. J., Susan, E. M., \& Kerri, H. S. (2010). The Impact of Blatant Stereotype Activation and Group Sex-Composition on Female Leaders. 21, 730-732. https://doi.org/10.1016/j.leaqua.2010.07.003

Daly, \& M (2005). Gender Mainstreaming in Theory and Practice. Social Politics: International Studies in Gender, State \& Society, 12, 433-450. https://doi.org/10.1093/sp/jxi023

Grosser, K., \& Moon, J. (2005). The Role of Corporate Social Responsibility in Gender Mainstreaming. International Feminist Journal of Politics, 7, 532-554. https://doi.org/10.1080/14616740500284524

Hoyt, C. L., \& Simon, S. (2011). Female Leaders. Psychology of Women Quarterly, 35, 143-157. https://doi.org/10.1177/0361684310385216

Offermann, L. R. (1986). Visibility and Evaluation of Female and Male Leaders. Sex Roles, 14, 533-543. https://doi.org/10.1007/BF00287453

Prudence, W. B. (2009). Gender Mainstreaming: What Is It (about) and Should We Continue Doing It? IDS Bulletin, 35, 65-72.

https://doi.org/10.1111/j.1759-5436.2004.tb00157.x 